\title{
Transvaginal and Transabdominal Ultrasonography of the Uterine Cervix During Pregnancy
}

\author{
H. Frank Andersen, MD
}

\begin{abstract}
Transvaginal and transabdominal ultrasound evaluation of the uterine cervix were compared in a study of 186 pregnant women. An empty bladder made transabdominal ultrasound measurement of the cervix more difficult, while bladder filling resulted in significant lengthening of the transabdominal cervical measurement. In contrast, transvaginal ultrasound cervical measurement was possible in all but 1 patient. Normal transvaginal ultrasound cervical measurements were significantly shorter on average than transabdominal cervical measurements, but compared closely with prior transabdominal ultrasound studies in which bladder filling was carefully controlled. Significant cervical shortening was not noted in most patients with a clinical diagnosis of incompetent cervix. Indexing Words: Obstetric ultrasound - Transvaginal ultrasound - Cervix uteri - Preterm birth - Uterine cervix length
\end{abstract}

Cervical shortening or effacement has been associated with an increased risk of preterm labor. ${ }^{1,2}$ Cervical shortening is usually determined by a manual vaginal examination and estimation of the length of the cervix, but manual examination is subjective and total cervical length cannot be measured when the cervix is closed. Ultrasound examination has the potential to provide objective estimates of cervical length.

The appearance and length of the normal cervix by transabdominal ultrasonography has been evaluated by previous investigators. ${ }^{3-7}$ In most of these studies examination of the cervix was performed with a full bladder, which improves visualization of the cervix but also distorts the cervical length., ${ }^{4-9}$ This inherent disadvantage of transabdominal ultrasonography of the cervix may in part explain the differing results of various studies of cervical length.

Transvaginal sonography can provide clear visualization of the uterine cervix with an empty bladder. ${ }^{10}$ Other investigators have noted that

From the Department of Obstetrics and Gynecology, The University of Michigan, Ann Arbor, Michigan. For reprints contact H. Frank Andersen, MD, Department of Obstetrics and Gynecology, L3221 Women's Hospital Box 0264, The University of Michigan, Ann Arbor, MI 48109 transvaginal ultrasound measurements of the cervix vary with parity and menstrual age, but normal values for transvaginal cervical measurements have not been established. ${ }^{11}$ This study evaluates a sample of pregnant women presenting for routine ultrasound examination throughout gestation in order to examine the variability in normal cervical length, and to compare transabdominal ultrasound and transvaginal ultrasound evaluation of cervical length.

\section{METHODS}

Women presenting for routine obstetrical ultrasound examination were recruited for study. Multiple gestations were excluded from the study. Some patients had more than one scan performed, but only the first scan with complete data for transabdominal and transvaginal ultrasound cervical evaluation was used.

Scans were performed using an Aloka 650 ultrasound unit. Transabdominal cervical measurement (ABDCX) was performed with a 3.5$\mathrm{MHz}$ curvilnear probe. The cervix was visualized and distance from internal to external os was measured (Figure 1). Women were asked not to void for 1 hour to 2 hours prior to examination, but a full bladder was not required. Bladder di- 


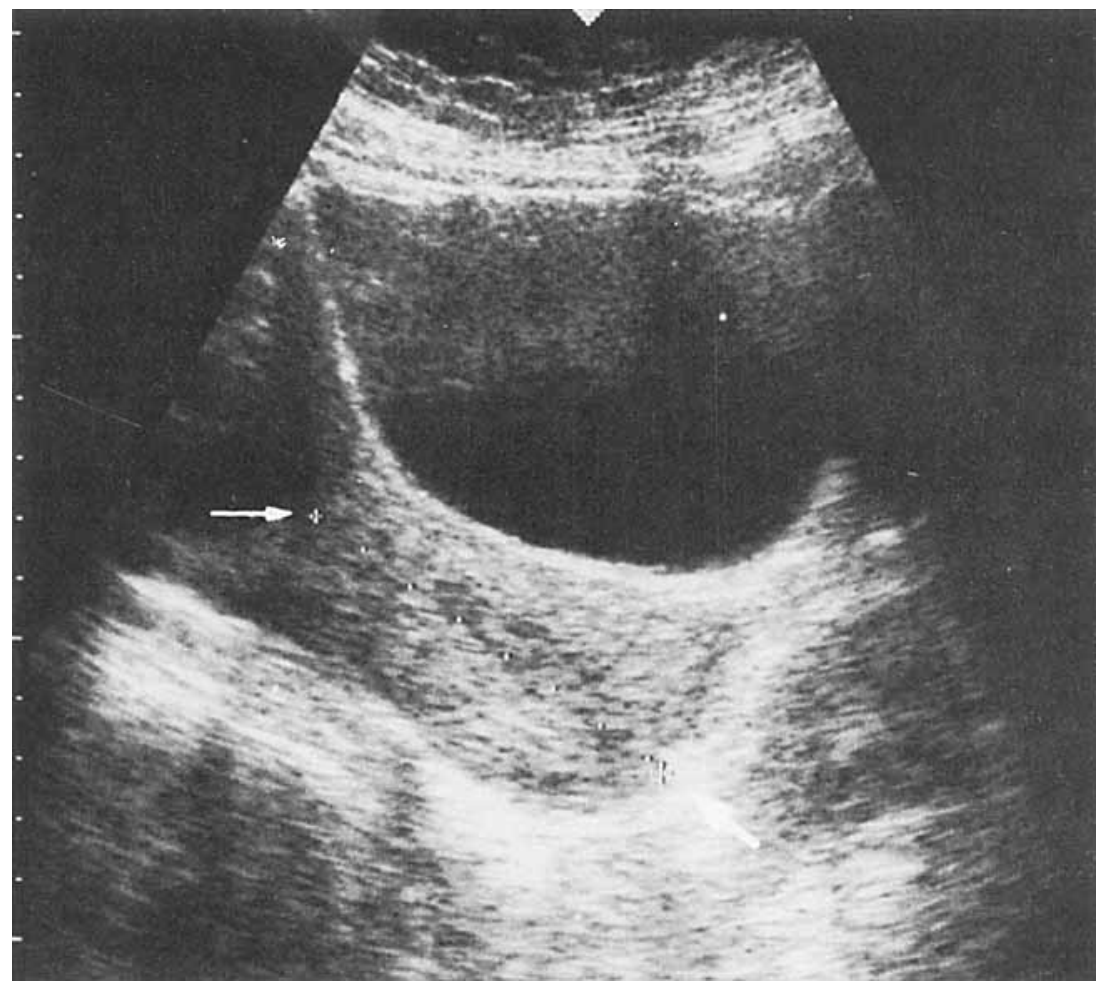

FIGURE 1. Transabdominal ultrasound of the uterine cervix. (Small arrow: internal cervical os. Large arrow: external cervical os.)

mensions (vertical and horizontal diameters) were measured, and a subjective estimate of bladder filling (empty, partial, full) was recorded. After the patient emptied her bladder the transvaginal cervical measurement (VAGCX) was made with a $5-\mathrm{MHz}$ vaginal probe attached to the Aloka 650 unit. The internal cervical os was seen in the sagittal plane and the probe then manipulated until the entire cervical canal could be visualized. Markers were placed at the furthest points at which the cervical canal walls were juxtaposed and the cervical length was measured (Figures 2 and 3). In some cases the cervix was too long to be entirely visualized in one scan. In these instances, a suitable structure, such as a mucous cyst, was used as a reference point, and measurements were made from the internal os and the external os to the reference point and added.

ABDCX and VAGCX measurements were attempted on each patient to allow paired comparisons. Measurements were performed twice by each method and the mean of the two measurements was used for each method. The difference between the two measurements was also recorded. All scans were performed by the same examiner.

Menstrual age was determined by the last

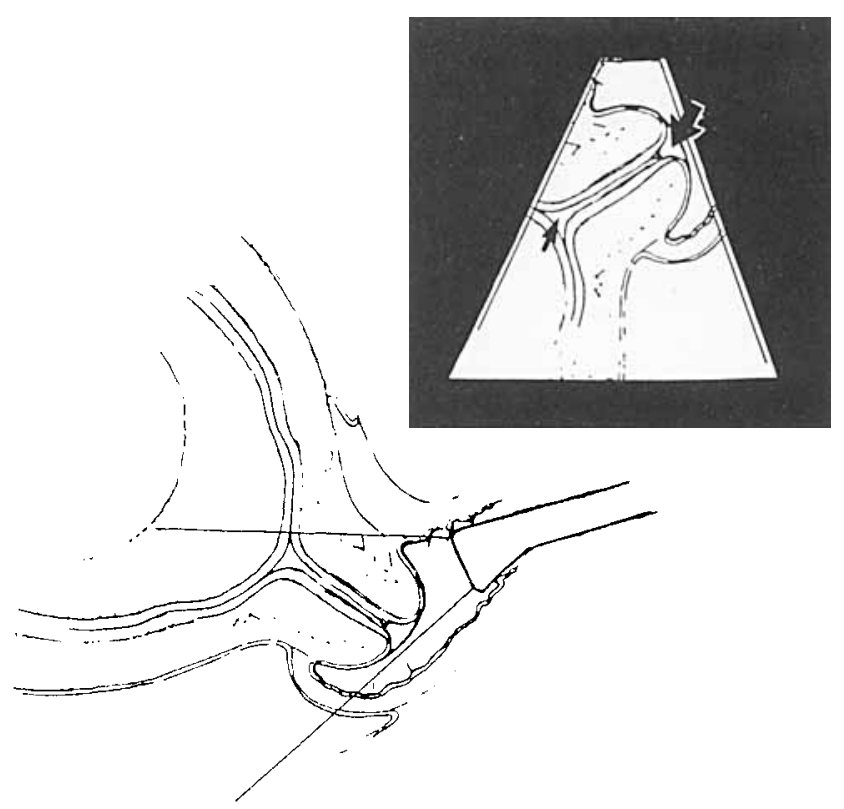

FIGURE 2. Diagram of method to visualize uterine cervix with transvaginal ultrasound. The inset represents the ultrasound picture; the small arrow points to the internal cervical os and the large arrow points to the external cervical os. 


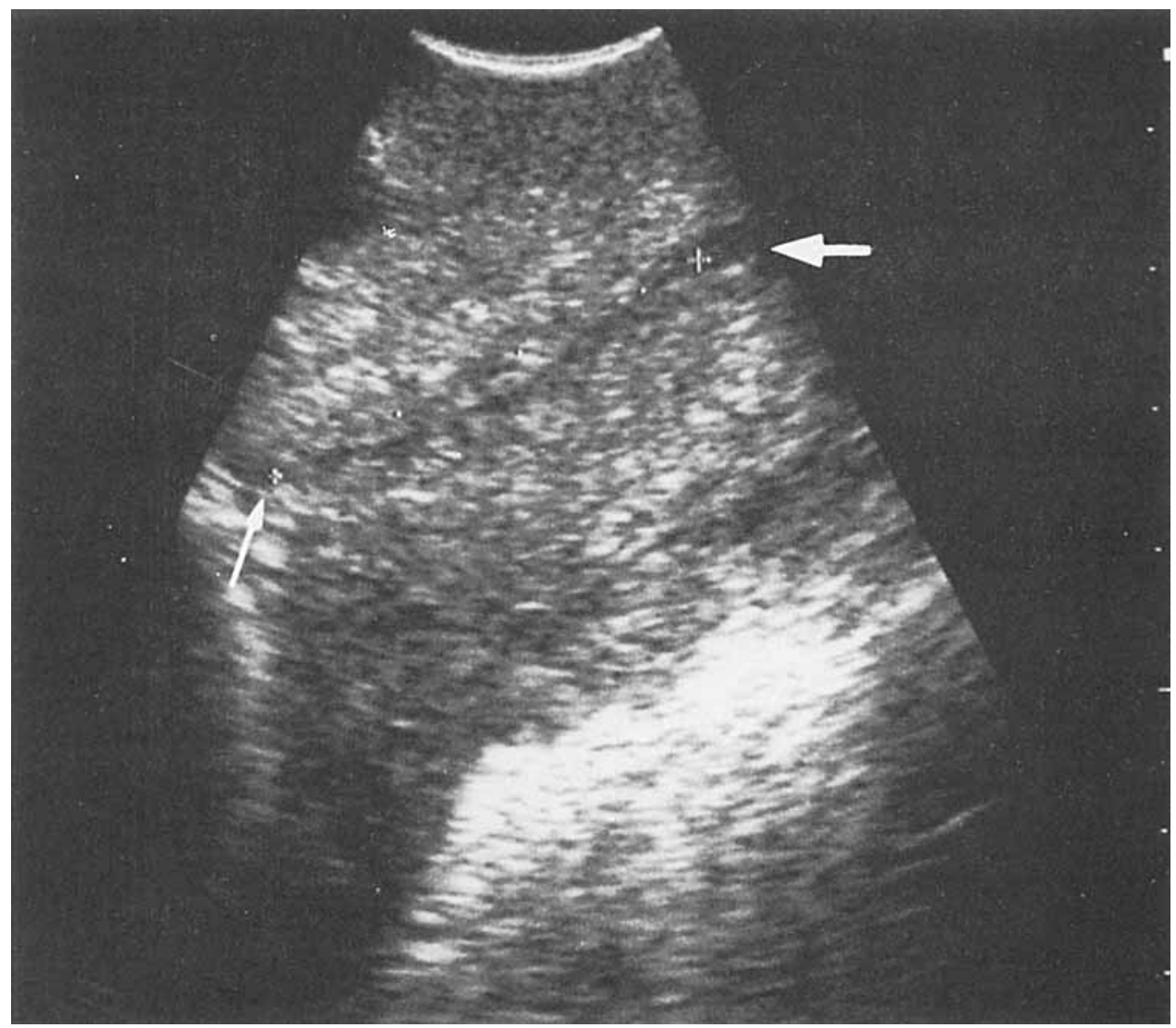

FIGURE 3. Transvaginal ultrasonography of the uterine cervix. (Small arrow: internal cervical os. Large arrow: external cervical os.) Cervical length is measured as the length of juxtaposed cervical canal walls.

menstrual period (LMP), unless the LMP was uncertain or the ultrasound estimate of menstrual age differed by more than 2 weeks in the first and second trimester or by more than 3 weeks in the third trimester, in which cases the ultrasound determination of menstrual age was used. The patient's obstetrical index (age, num-

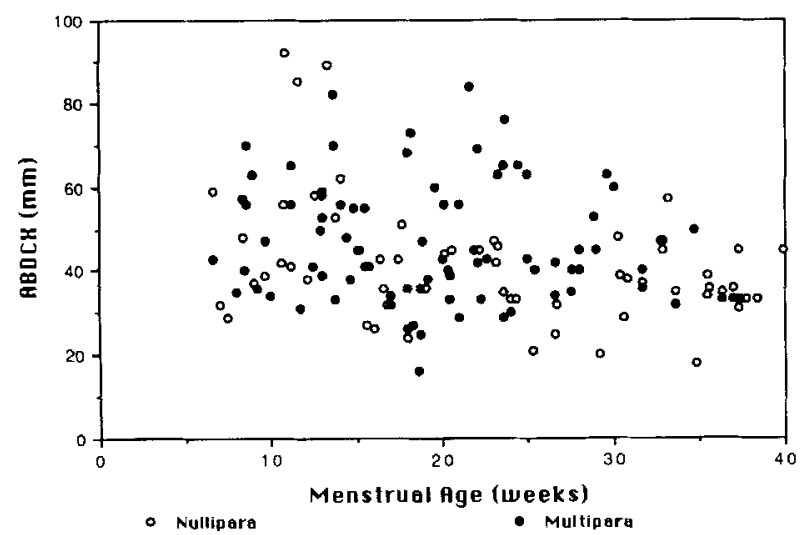

FIGURE 4. Scattergram of transabdominal ultrasound measurements of the cervix throughout gestation in 143 women. (Open circles: primiparae. Solid circles: multiparae. Crosses: 8 patients with incompetent cervix.) ber of prior term deliveries, preterm deliveries, abortions, and ectopic pregnancies) was routinely recorded with the ultrasound report. Data on cervical length were not reported back to the patient's physician unless specifically requested. Informed consent was obtained for this study,

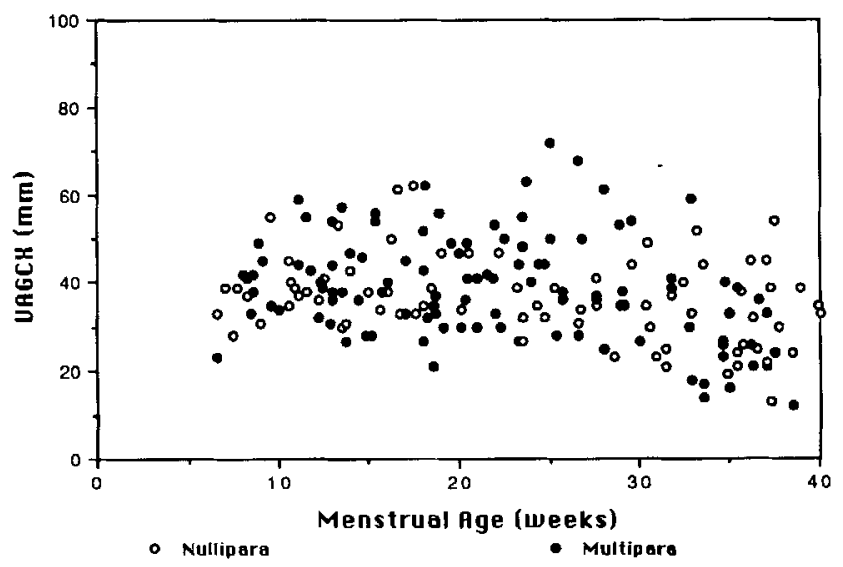

FIGURE 5. Scattergram of transvaginal ultrasound measurements of the cervix throughout gestation in 185 women. (Open circles: primiparae. Solid circles: multiparae. Crosses: 8 patients with incompetent cervix.) 


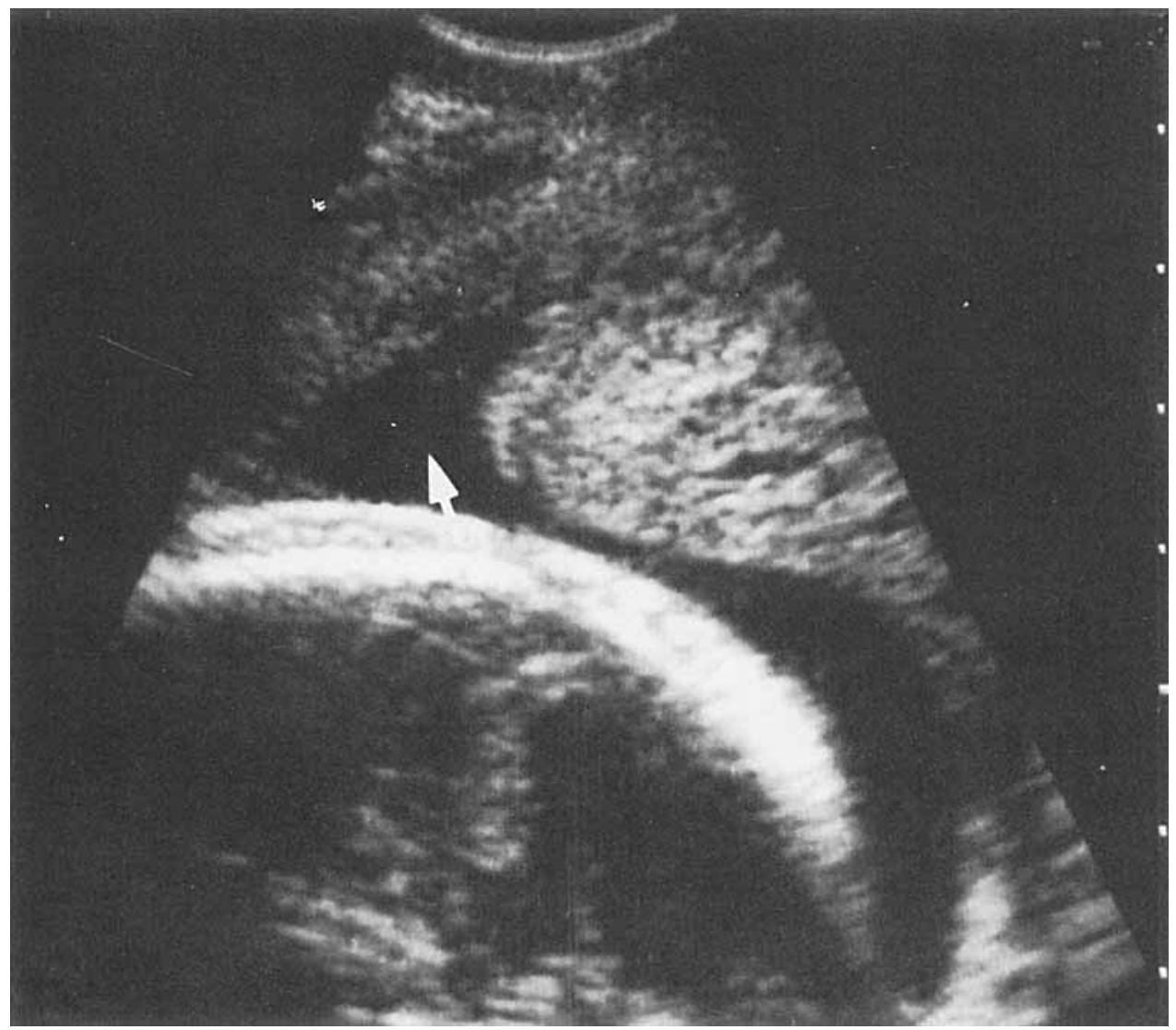

FIGURE 6. Example of funneling of the internal cervical os (arrow), as visualized by transvaginal ultrasound at 27 weeks, menstrual age. The external cervical os is not seen in this scan. This patient delivered at term without complication.

which was approved by the institutional review board.

Data was analyzed using a standard microcomputer statistical package. ${ }^{12}$ Statistical comparisons were made using Student's $t$ test for nonpaired data, paired $t$ test for paired comparisons, and chi square analysis for categorical data. A $p$ value $<0.05$ was used to reject the null hypothesis of no difference.

\section{RESULTS}

The number of patients examined was $186 ; 81$ patients were nulliparous and 105 had a prior birth, of which 27 included a prior preterm delivery. 67 patients had a prior abortion (spontaneous or induced). The age range of the patients was 16 to 39 years (mean age $=26 \mathrm{yr}$, one standard deviation $=5.0 \mathrm{yr}$ ). Eight patients later had a cervical cerclage placed because of a history suggestive of incompetent cervix or a clinical examination revealing painless cervical dilatation in the second trimester.
These eight patients were excluded from the group used to determine normal cervical lengths.

Visualization of the cervix by transabdominal ultrasonography was dependent on bladder filling. With the bladder empty, an ABDCX measurement could be obtained in only $46 \%(25 / 55)$ of patients, with a partially full bladder ABDCX measurement was possible in $86 \%(65 / 76)$, and with a full bladder the cervix was visualized $96 \%$ $(50 / 52)$ of the time $(p<0.01)$. VAGCX measurement was possible in all but $1(99.5 \%)$ of the patients; in this patient, the vaginal measurement was not possible because the patient had severe constipation and the transvaginal scan caused undue discomfort.

Scattergrams of ABDCX and VAGCX measurements are presented in Figures 4 and 5. Sporadic $A B D C X$ measurements revealed a very long cervix and it was hypothesized that this might be due to bladder filling. Linear regression analysis showed a correlation between bladder filling and the ABDCX measurement. The strongest correlation was between the horizontal di- 
TABLE 1

Cervical Length Measurements by Trimester of Gestation ${ }^{\mathrm{a}}$

\begin{tabular}{|c|c|c|c|}
\hline & \multicolumn{3}{|c|}{ Trimester } \\
\hline & 1: 6 wks to 13.9 wks, MA & $2: 14$ wks to 27.9 wks, MA & $3: 28$ wks to 40 wks, MA \\
\hline \multicolumn{4}{|l|}{ ABDCX } \\
\hline $\mathbf{N}$ & 32 & 67 & 36 \\
\hline Mean (mm) & 53.2 & 43.7 & 39.5 \\
\hline $\mathrm{SD}(\mathrm{mm})$ & 16.9 & 13.8 & 9.8 \\
\hline \multicolumn{4}{|l|}{ Range } \\
\hline Minimum length (mm) & 29.0 & 21.0 & 18.0 \\
\hline Maximum length (mm) & 92.0 & 84.0 & 63.0 \\
\hline \multicolumn{4}{|l|}{ VAGCX } \\
\hline$N$ & 38 & 77 & 62 \\
\hline Mean $(\mathrm{mm})$ & 39.8 & 41.6 & 32.3 \\
\hline $\mathrm{SD}(\mathrm{mm})$ & 8.5 & 10.2 & 11.6 \\
\hline \multicolumn{4}{|l|}{ Range } \\
\hline Minimum length (mm) & 23.0 & 27.0 & 12.0 \\
\hline Maximum length (mm) & 59.0 & 72.0 & 61.0 \\
\hline
\end{tabular}

${ }^{a}$ Eight patients who had cervical cerclage placed were excluded. ABDCX: transabdominal cervical length measurements. VAGCX: Transvaginal ultrasound cervical length measurements. MA: menstrual age. Numbers of ABDCX and VAGCX measurements are not equal because of failure to visualize the cervix in some instances.

ameter of the bladder and the ABDCX measurement $\left(r^{2}=0.17, p<0.01\right)$.

One finding noted was occasional funneling of the internal cervical os (Figure 6). This was seen on transvaginal sonography in 22 of the 178 patients who did not require cervical cerclage and in 3 of the 8 patients who required cerclage. An additional 17 patients had a very slight degree of funneling noted on vaginal scanning. This finding was observed on transabdominal scanning in 7 patients.

Table 1 presents normative data for cervical length measured by both methods. On average ABDCX measurements were significantly longer than VAGCX measurements (mean difference $=$ $5.2 \mathrm{~mm}$, one $\mathrm{SD}=14.3, p<0.001$ by paired $t$ test).

Most of the cervical measurements were repeated and the difference (range) between the two measurements was noted. Pairs of ABDCX measurements had an average difference of 3.5 $\mathrm{mm}$ (one $\mathrm{SD}=3.0$ ) and VAGCX measurements had an average difference of $2.3 \mathrm{~mm}$ (one $\mathrm{SD}=$ 2.0). The larger difference in repeat ABDCX measurements was statistically significant $(p<$ 0.01).

Retrospective analysis of obstetrical historical information and cervical length are presented in Table 2. Mean cervical length was statistically significantly longer among multiparous women compared to primiparous women. Mean cervical length among the 8 patients who later had a cervical cerclage placed approached a statistically significant difference when compared to the patients examined prior to 28 weeks, menstrual age, who did not require cerclage. In both com- parisons the standard deviations are larger than the differences between the means, indicating a considerable overlap between the groups.

\section{DISCUSSION}

Ultrasound examination of the cervix may have potential use as a predictor of preterm delivery, a major cause of perinatal morbidity and mortality. Efforts to predict patients at risk for preterm labor by various historical and current risk factors have had only partial success. ${ }^{13,14}$ Several authors have noted that cervical effacement or dilatation is associated with increased risk of preterm delivery, but others feel that cervical effacement is a normal occurrence as pregnancy progresses. ${ }^{1,2}$

Prior studies of ultrasonically measured cervical dimensions have had differing results. Zemlyn reported that the average cervical length was $37 \mathrm{~mm}$ in a study of 100 patients. ${ }^{3}$ Bowie et al. found similar results, the mean cervical length $=32.5 \mathrm{~mm}(\mathrm{~N}=30)$ with the bladder empty; with the bladder partially filled, the mean length was $46 \mathrm{~mm} .{ }^{4}$ A third study of 30 women reported a mean cervical length of approximately $35 \mathrm{~mm}$ (one $\mathrm{SD}=3.5 \mathrm{~mm}$ ). ${ }^{5}$ Both Zemlyn and Varma et al. noted the effect of bladder filling on cervical length. In contrast to the previous findings, Podobnik et al. determined average cervical length to be $48 \mathrm{~mm}$ (one SD deviation $=3.2 \mathrm{~mm}){ }^{7}$ Their measurements were made with a full bladder and they noted that emptying the bladder reduced the average cervical length by approximately $5 \mathrm{~mm}$. Ayers et al. reported that the average cervical length was 52 
TABLE 2

Restrospective Comparisons of Cervical Length Measurements by Parity (All Patients), and Between

Patients Requiring Cervical Cerclage for Historical and Clinical Evidence of Incompetent Cervix and Patients Without Cerclage, Examined by 28 Weeks, Menstrual Age (MA) ${ }^{\mathrm{a}}$

\begin{tabular}{|c|c|c|c|}
\hline & Nulliparous & Multip & \\
\hline \multicolumn{4}{|l|}{$A B D C X$} \\
\hline $\mathrm{N}$ & 57 & 78 & \multirow{4}{*}{$p=.03$} \\
\hline Mean $(\mathrm{mm})$ & 41.6 & 47.2 & \\
\hline $\mathrm{SD}(\mathrm{mm})$ & 14.8 & 13.8 & \\
\hline Range (mm) & 18.0 to 92.0 & 25.0 to 84.0 & \\
\hline \multicolumn{4}{|l|}{ VAGCX } \\
\hline $\mathrm{N}$ & 79 & 98 & \multirow{4}{*}{$p=.03$} \\
\hline Mean (mm) & 35.8 & 39.6 & \\
\hline $\mathrm{SD}(\mathrm{mm})$ & 9.7 & 12.1 & \\
\hline \multirow[t]{2}{*}{ Range $(\mathrm{mm})$} & 13.0 to 62.0 & 12.0 to 72.0 & \\
\hline & Future Cerclage & \multicolumn{2}{|c|}{$\begin{array}{c}\text { No Cerclage }(<28 \\
\text { Weeks, MA) }\end{array}$} \\
\hline \multicolumn{4}{|l|}{$A B D C X$} \\
\hline $\mathrm{N}$ & 8 & 99 & \multirow{4}{*}{$p=.06$} \\
\hline Mean $(\mathrm{mm})$ & 36.3 & 46.8 & \\
\hline $\mathrm{SD}(\mathrm{mm})$ & 14.3 & 15.4 & \\
\hline Range (mm) & 16.0 to 59.0 & 21.0 to 92.0 & \\
\hline \multicolumn{4}{|l|}{ VAGCX } \\
\hline $\mathrm{N}$ & 8 & 115 & \multirow{4}{*}{$p=.07$} \\
\hline Mean $(\mathrm{mm})$ & 34.5 & 41.0 & \\
\hline SD (mm) & 8.6 & 9.7 & \\
\hline Range $(\mathrm{mm})$ & 21.0 to 44.0 & 23.0 to 72.0 & \\
\hline
\end{tabular}

${ }^{a}$ Future cerclage patients were evaluated before cerclage placement

$\mathrm{mm}$ in 142 patients; a cervical length of $40 \mathrm{~mm}$ was two SDs below the mean. ${ }^{6}$ All patients in that study had their bladder filled to a diameter of $45 \mathrm{~mm}$ to $60 \mathrm{~mm}$. ${ }^{6}$ As noted in this study and by earlier investigators, the degree of bladder filling has a significant effect on the measurement of cervical length by transabdominal ultrasonography. $4,8,9$ Since it is difficult to standardize bladder volume, differences in bladder filling could explain the differences in mean cervical length among these studies.

Transvaginal ultrasonography has several advantages over transabdominal ultrasonography for evaluation of the cervix. The proximity and optimal focal length allow close identification of the cervix and inspection of the canal and internal os. Scanning with an empty bladder removes this confounding variable in assessing cervical length, while visualization of the cervix is possible in nearly all patients. The average VAGCX lengths determined in this study are similar to those found by Zemlyn, Varma, and Bowie.

This study found a larger standard deviation among cervical length measurements than previous investigators. Several of the earlier studies analyzed repeated measurements on individual patients. ${ }^{5-7}$ This may introduce bias and artificially reduces variance in the results. Some also excluded patients who delivered preterm from their analysis. ${ }^{6,7}$ Since it is not possible to predict outcomes at the time of ultrasonography, normal values based on a selected group are more difficult to use. Our data describe a crosssection of pregnant women (one measurement per subject). It is noteworthy that there is a large degree of variation in cervical length among pregnant women at all menstrual ages. Although a trend toward cervical shortening with increasing menstrual age beyond 28 weeks is suggested by visual inspection of Figures 4 and 5 , well-designed longitudinal studies, with serial measurements of cervical length, are needed to accurately define the significance of changes in cervical length during pregnancy.

Several previous investigators have suggested that ultrasound findings may be used to identify patients with incompetent cervix. ${ }^{6,7,15-18}$ Dilatation of the endocervical canal with prolapse of amniotic membranes is an obvious, but uncommon, indication of impending preterm delivery. Some authors suggest that dilatation of the cervical canal or internal cervical os indicates incompetence. As noted in Figure 3, the normal cervical canal appears to be collapsed in a narrow line. The occasional finding of a difference in the texture of the cervix immediately surrounding the cervical canal (perhaps due to endocervical glands) could explain the appearance of a normally dilated cervical canal in studies with transabdominal ultrasound. Retrospective comparison of the 8 cerclage patients in this study with those without incompetent cervix failed to demonstrate a statistically significant difference because of the small number of patients. Also, a considerable overlap between the two groups (Table 2) was seen. Suggestions that cervical length $<34 \mathrm{~mm},{ }^{7}$ or $<40 \mathrm{~mm},{ }^{6}$ indicate cervical incompetence, and require cerclage seem somewhat extreme in light of these findings.

Despite the statistical difference in mean cervical length between nulliparous and multiparous women, there is considerable overlap between the groups. In particular, transvaginal ultrasonography showed only a $4 \mathrm{~mm}(10 \%)$ difference in the mean cervical length between the two groups; therefore, it does not seem justified to establish separate normal values for primiparous and multiparous patients at present.

This study demonstrates that transvaginal ultrasonography can provide accurate estimates of cervical length, without the confounding influence of bladder filling. These data provide nor- 
mal values for cervical length measured by transvaginal ultrasonography in patients with singleton gestations. The predictive value of cervical length for pregnancy outcome was not determined by this study. Further study is clearly necessary to determine the value of serial cervical length measurements and the implications of change in cervical length during gestation.

\section{REFERENCES}

1. Stubbs TM, VanDorsten P, Miller MC: The preterm cervix and preterm labor: Relative risks, predictive values, and change over time. Am J Obstet Gynecol 155:829-834, 1986.

2. Papiernik E, Bouyer J, Collin D, et al: Precocious cervical ripening and preterm labor. Obstet Gynecol 67:238-242, 1986.

3. Zemlyn S: The length of the uterine cervix and its significance. J Clin Ultrasound 9:267-269, 1981.

4. Bowie JD, Andreotti RF, Rosenberg ER: Sonographic appearance of the uterine cervix in pregnancy: The vertical cervix. AJR 140:737-740, 1983.

5. Varma TR, Patel RH, Pillai U: Ultrasonic assessment of cervix in normal pregnancy. Acta Obstet Gynecol Scand 65:229-331, 1986.

6. Ayers JW, DeGrood RM, Compton AA, et al: Sonographic evaluation of cervical length in pregnancy: Diagnosis and management of preterm cervical effacement in patients at risk for premature delivery. Obstet Gynecol 71:939-944, 1988.

7. Podobnik M, Bulic M, Smiljanic N, et al: Ultrasonography in the detection of cervical incompetency. J Clin Ultrasound 13:383-391, 1988.
8. Zemlyn S: The effect of the urinary bladder in obstetrical sonography. Radiology 128:169-175, 1978.

9. Confino E, Mayden KL, Giglia RV, et al: Pitfalls in sonographic imaging of the incompetent Uterine cervix. Acta Obstet Gynecol Scand 65:593$597,1986$.

10. Timor-Tritsch IE, Rottem S, Boldes R: Scanning the uterus, in Transvaginal Ultrasonography, Timor-Tritsch IE, Rottem S (eds). New York, Elsevier, 1988, p 31.

11. Goldstein SR: Endovaginal Ultrasound. New York, Alan R Liss, 1988, p 77.

12. Wilkinson, L: SYSTAT: The System for Statistics. Evanston, IL, Systat, 1987.

13. Main DM, Richardson D, Gabbe SG, et al: Prospective evaluation of a risk scoring system for predicting preterm delivery in black inner city women. Obstet Gynecol 69:61-66, 1987.

14. Holbrook RH, Laros RK, Jr, Creasy RK: Evaluation of a risk-scoring system for prediction of preterm labor. Am J Perinatol 6:62-68, 1989.

15. Sarti DA, Sample WF, Hobel CJ, et al: Ultrasonic visualization of a dilated cervix during pregnancy 1. Radiology 130:417-420, 1979.

16. Brook I, Feingold M, Schwartz A: Ultrasonography in the diagnosis of cervical incompetence in pregnancy-A new diagnostic approach. $\mathrm{Br} J \mathrm{Ob}$ stet Gynaecol 88:640-643, 1981.

17. Vaalamo P, Kivikoski A: The incompetent cervix during pregnancy diagnosed by ultrasound. Acta Obstet Gynecol Scand 62:19-21, 1983.

18. Varma TR, Patel RH, Pillai U: Ultrasonic assessment of cervix in 'at risk' patients. Acta Obstet Gynecol Scan 65:174-152, 1986. 